\title{
Permeable channel cross section for maximizing stormwater infiltration and seepage rates
}

\begin{abstract}
Maximization of infiltration and seepage rates is important to better control the quantity of stormwater to foster sustainable urban stormwater management. In this study, the effect of the cross-sectional flow area of a permeable channel on seepage rate was investigated to improve the efficiency of permeable stormwater channels. Physical models under ponding were used to examine seepage of earthen trapezoidal channels with various initial water levels, base widths, and side slopes. Regression analysis was used to develop an equation for predicting the rate of the unsteady seepage over time, and the equation was used to examine several cases of different flow cross-sectional areas and channel dimensions. The results showed that the channel side slope significantly affected the cumulative seepage volume. For a given top width, decreasing the base width and increasing the side slope resulted in an increase in the unsteady seepage rate.
\end{abstract}

Keyword: Crossflow; Infiltration; Stormwater 